\title{
NILAI EKONOMI PERIKANAN CUCUT DAN PARI DAN IMPLIKASI PENGELOLAANNYA
}

\author{
Oleh : \\ Agus Heri Purnomo' dan Tenny Apriliani ${ }^{1}$
}

\begin{abstract}
ABSTRAK
Kajian ini menganalisis aspek sosial ekonomi perikanan cucut dan ikan pari di Indonesia, terkait dengan relevansi aspek tersebut dalam rencana aksi nasional (national plan of action, NPOA) untuk sumberdaya elasmobranchii. Pengambilan data dilakukan pada periode Agustus 2004 - November 2005 di lokasi-lokasi pendaratan utama, yaitu Tanjung Luar (NTB), Kedonganan (Bali), Sungai Kakap (Kalbar), Sungai Liat (Bangka Belitung), Muara Angke (Jakarta) dan Batang (Jateng) serta beberapa lokasi pendukung. Analisis deskriptif tabulatif yang dilakukan terhadap data-data tersebut, menunjukkan bahwa produksi cucut dan ikan pari memberikan kontribusi signifikan terhadap pendapatan nelayan, baik yang menangkap cucut sebagai target utama maupun hasil sampingan. Di lokasi dimana cucut atau pari merupakan target utama, yaitu Tanjung Luar, Sungai Liat, dan Sungai Kakap, setiap ABK memperoleh pendapatan berturut-turut sebesar Rp 20,8 juta, Rp 24,1 juta dan Rp 8,5 juta per tahun. Nilai ini sebanding dengan tambahan pendapatan yang diperoleh ABK di lokasi dimana cucut atau pari merupakan hasil samping (Kedonganan dan Batang), yakni sebesar masing-masing Rp 27,7 juta dan Rp 22,4 juta pertahun. Nilai ekonomi perikanan cucut dan pari juga terkait dengan nilai tambah dari aktivitas pengolah, pengrajin, tukang potong, kuli angkut, dsb. Hasil analisis selanjutnya menunjukkan adanya peluang untuk menyusun sebuah NPOA yang selaras dengan kepentingan ekonomi nelayan, misalnya dengan meningkatkan nilai tambah hasil tangkapan sehingga penurunan volume tangkapan tidak harus menyebabkan turunnya pendapatan. Sejauh ini, nilai tambah perikanan cucut dan pari bervariasi; misalnya, 3,5\% untuk cucut dan $23 \%$ untuk pari di Kedonganan, jauh dibawah nilai tambah cucut di Sungai Kakap (290\%) dan pari di Batang $(75 \%)$. Implikasi dari hasil ini adalah pentingnya upaya penciptaan nilai tambah disamping perlunya kajian lanjutan untuk merumuskan mekanisme teknis untuk mengurangi volume produksi sesuai dengan kondisi lapang.
\end{abstract}

Kata Kunci : Nilai Ekonomi, Cucut, Pari, Elasmobranchii, Pengelolaan Perikanan.

\section{Abstract : Economic Value of the Shark and Ray Fishery and their Management Implication by Agus Heri Purnomo and Tenny Apriliani}

This study analyses the socio-economic aspects of Indonesian shark and ray fisheries as related to the relevance of these aspects in a National Plan of Action (NPOA) for elasmobranchii resources. Data were collected in the period of August 2004 to November 2005 in primary shark and ray landing places, namely Tanjung Luar (NTB), Kedonganan (Bali), Sungai Kakap (Kalbar), Sungai Liat (Bangka Belitung), Muara Angke (Jakarta) and Batang (Jateng) and a number of complementary locations. A tabulated-descriptive analysis shows that shark and ray production contributes significantly to the income of the fishers, both who produce shark and ray as main targets and by-catches. In locations where shark or ray is the main target, namely Tanjung Luar, Sungai Liat, dan Sungai Kakap, an individual crew fisher would, respectively, earn as much as $R p 20.8$ million, $R p 24.1$ million and $R p 8.5$ million annually. These values by and large match with the annual additional income earned by every crew producing shark or ray as by-catch in Kedonganan and Batang, who would receive Rp 27.7 million and Rp 22.4 million. A further analysis shows an opportunity to formulate an NPOA which is parallel with the fishers' economic interests, namely through the improvement of added values in such a way that reduction in catch will not necessarily cause decrease in income. So far, the value added for fisheries commodities is various; for example, $3.5 \%$ for shark and $23 \%$ for ray in Kedonganan, as compared to shark value added in Sungai Kakap (290\%) and ray value added in Batang (75\%). The implication of this research is that efforts directed to the creation of value added and the formulation of technical mechanism to reduce production become essential in developing a workable NPOA.

\section{Keywords : Economic Value, Shark, Ray, Elasmobranchii, Fishery Management}




\section{PENDAHULUAN}

Perkembangan perikanan elasmobranchi, terutama cucut dan ikan pari, telah memunculkan kekhawatiran masyarakat perikanan dan pemerhati masalah lingkungan. Meskipun penangkapan cucut dan ikan pari telah dilakukan secara berabad-abad, kecenderungan terbaru menunjukkan adanya peningkatan intensitas penangkapan di seluruh dunia. Hal ini terutama didorong oleh terbukanya pasar internasional dengan harga yang semakin kompetitif diikuti penggunaan teknologi yang semakin efektif dan wilayah penangkapan yang semakin meluas.

Dari sudut pandang biologi, kekhawatiran tersebut terutama dikaitkan dengan beberapa karakteristik reproduksi dan pertumbuhan elasmobranchi, terutama jenis cucut. Stok cucut pada umumnya menunjukkan laju pulih yang lambat karena lambatnya proses kematangan seksual dan sedikitnya anakan yang dihasilkan. Kenyataan tersebut mendorong masyarakat perikanan dunia untuk mengupayakan sebuah kesepakatan tentang pengelolaan sumberdaya ini. Dalam perkembangannya, langkah yang telah ditempuh oleh masyarakat perikanan tersebut berhasil memaksa FAO (Food and Agricultural Organization) untuk merumuskan garis-garis besar yang mengarah pada langkah pengelolaan bersama secara internasional. Garis besar tersebut lebih lanjut berkembang menjadi sebuah dokumen yang disebut sebagai International Plan of Action for Conservation and Management of Sharks (IPOA-SHARKS) (Anonim, 1998). Istilah 'shark' dalam kesepakatan tersebut mencakup spesies-spesies yang tergabung dalam kelas Chondroichtyes, yaitu berbagai jenis ikan cucut dan pari.

Rencana aksi tersebut bersifat sukarela tetapi diharapkan dapat diimplementasikan di segenap negara yang memiliki keterkaitan dengan perikanan cucut, melalui rencana di tingkat nasional (National Plan of Action, NPOA). Negaranegara yang telah mengimplementasikan kesepakatan tersebut diharuskan untuk menerapkan berbagai kebijakan yang pada intinya ditujukan untuk menjaga kelestarian sumberdaya cucut sebagaimana dijelaskan dalam cakupan istilah tersebut di atas. Indonesia telah menyusun draft NPOA (Anonimous, 2006), yang diharapkan dapat mendasari pelaksanaan pengelolaan sumberdaya elasmobranchi di Indonesia dengan baik.

Perikanan cucut, dalam artian yang lebih luas sebagaimana dimaksudkan dalam IPOA, jelas tidak hanya membawa manfaat ekonomi bagi pelaku-pelaku usaha langsung seperti para penangkap dan pengolahnya. Selain membuka peluang usaha bagi industri pengolahan atau bahkan kerajinan (misalnya kulit pari dan kulit cucut), eksploitasi cucut juga membuka peluang usaha pelengkapnya, misalnya usaha pemasaran dan ekspor. Berbagai lapangan kerja yang teridentifikasi berkembang sejalan dengan berkembangnya penangkapan cucut adalah di antaranya penangkap itu sendiri, jasa pengadaan alat tangkap, pengecer, pengumpul, pengolah, dan eksportir. Namun di banyak lokasi, penangkapan cucut bahkan dilakukan hanya untuk mendaratkan bagian yang paling bernilai ekonomis saja, misalnya sirip. Sementara itu, bagian lain seringkali dibuang di laut.

Secara teoritis, perumusan rencana semacam itu tidak terlalu sulit untuk dipahami dan dilaksanakan. Namun demikian, penerapannya tidak mudah karena terkait dengan berbagai aspek, terutama sosial ekonomi dalam hubungannya dengan kontribusi dan peran penangkapan cucut terhadap nelayan di sejumlah besar negara berkembang. Tujuan penelitian ini adalah untuk mendapatkan data dan informasi yang akurat mengenai 
kegiatan penangkapan ikan cucut dan pari serta optimalisasi pemanfaatkan terkait dengan adanya kebijakan tingkat nasional pengelolaan kelestarian sumberdaya cucut dan pari. Terkait dengan itu, makalah ini mengungkapkan beberapa aspek sosial ekonomi yang diperkirakan akan bersinggungan dengan segala bentuk pengaturan / pengelolaan sumberdaya cucut.

\section{METODE}

\section{Lokasi dan Waktu Penelitian}

Penelitian ini dilaksanakan pada periode Agustus 2004 s/d November 2005 di lokasi-lokasi penting pendaratan ikan cucut dan atau pari, yaitu Tanjung Luar (Propinsi Nusa Tenggara Barat), Kedonganan (Propinsi Bali), Sungai Kakap (Propinsi Kalimantan Barat), Sungai Liat (Propinsi Bangka Belitung), Muara Angke (Propinsi DKI Jakarta) dan Batang (Propinsi Jawa Tengah).

\section{Jenis dan Sumber Data}

Data yang dikumpulkan berupa data primer dan data sekunder. Data primer yang dikumpulkan mencakup nilai ekonomis penangkapan ikan cucut dan pari pada lokasilokasi penelitian yang diperoleh berdasarkan hasil wawancara dengan responden terkait. Sementara itu data sekunder yang dikumpulkan berupa dokumen dari instansi perikanan setempat seperti Dinas Perikanan dan Kelautan dan Tempat Pelelangan Ikan pada setiap lokasi penelitian serta data dan informasi dari BPS, perguruan tinggi dan berbagai instansi lainnya.

\section{Metode Pengumpulan dan Analisis Data}

Penelitian ini merupakan kajian deskriptif tabulatif berdasarkan hasil survai. Penggalian data di semua lokasi berlangsung masing-masing selama 10 - 14 hari, melalui wawancara menggunakan kuesioner dengan responden yang diambil secara purposif untuk mewakili berbagai pelaku usaha yang terkait dengan perikanan cucut dan ikan pari di wilayah tersebut. Responden yang dipilih meliputi juragan, nakhoda, anak buah kapal (ABK), pedagang pengumpul, pengecer, eksportir dan pengolah. Jumlah responden untuk setiap lokasi dan pelaku usaha berbeda, hal ini dikarenakan waktu penangkapan cucut dan pari cukup lama sehingga jumlah responden sangat bergantung pada saat pendaratan ikan. Data primer yang dikumpulkan berupa pendapatan usaha dari setiap kegiatan, sistem bagi hasil yang berlaku, pemanfaatan ikan cucut dan pari hasil tangkap serta produksi hasil tangkapan di setiap lokasi riset. Selain data-data primer, dikumpulkan pula data-data sekunder yang diperoleh dari Dinas Kelautan dan Perikanan setempat dan data-data pelengkap yang diperoleh dari beberapa lokasi pendukung, misalnya Muara Kintap dan Kurau (Kalimantan Selatan) dan Pangkalpinang (Bangka Belitung). Data sekunder yang terkumpul meliputi data perkembangan produksi dan nilai produksi ikan cucut dan pari yang dan data mengenai volume dan nilai ekspor perikanan. Analisis data yang dilakukan berupa analisis deskriptif tabulatif terhadap data-data yang terkumpul. Kemudian Penyimpulan dilakukan melalui interpretasi logis terhadap hasil tabulasi data yang ditampilkan dalam bentuk diagram dan matriks dan catatan lapang yang diperoleh selama penelitian.

\section{HASIL DAN PEMBAHASAN}

\section{Perkembangan Perikanan Cucut}

Data-data perikanan Indonesia sejauh ini menunjukkan bahwa cucut menempati posisi penting di antara berbagai komoditas ekspor perikanan lainnya. Sebagai ilustrasi, Gambar 1 dan 2 memperlihatkan posisi volume dan nilai ekspor produk cucut dibandingkan dengan salah satu komoditas andalan ekspor, yaitu rumput laut, dan komoditas lain yang volume ekspornya hampir sama rendah dengan volume ekspor produk 


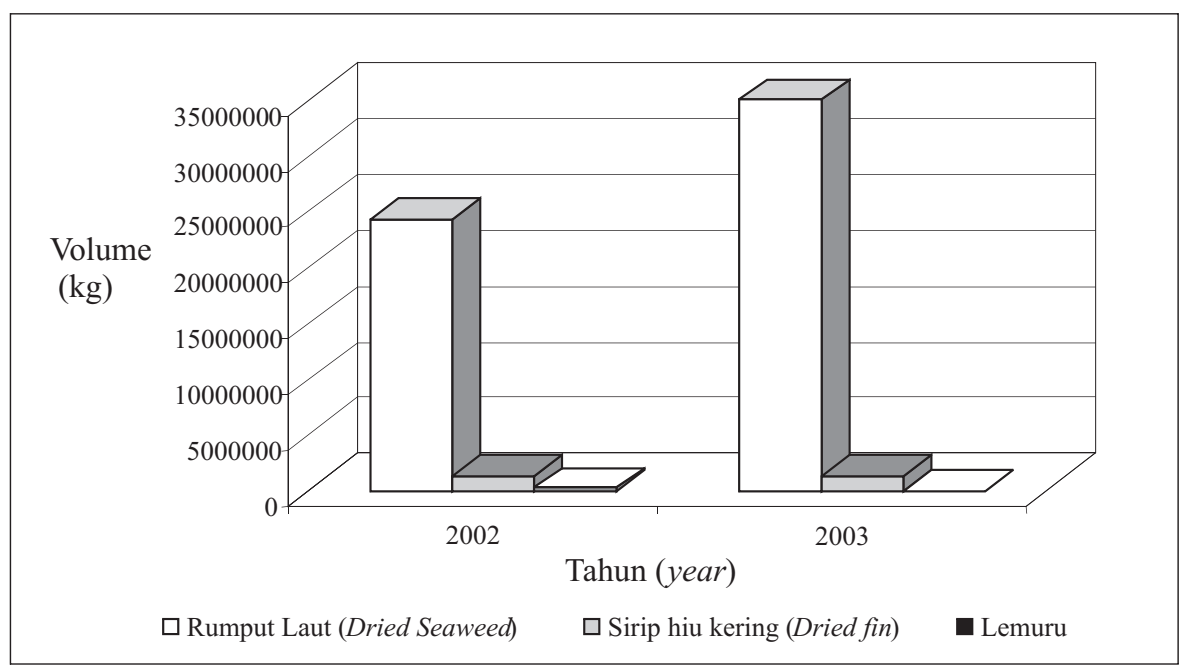

Sumber : Anonim (2003a) \& Anonim (2004b) diolah

Source : Anonimous (2003a) and Anonimous (2004b), processed

\section{Gambar 1. Volume Ekspor Sirip Cucut dan Dua Komoditas Pembanding di Indonesia, 2002-2003}

Figure 1. Export Volume of Shark Fin and Two Comparing Commodities in Indonesia, 20022003

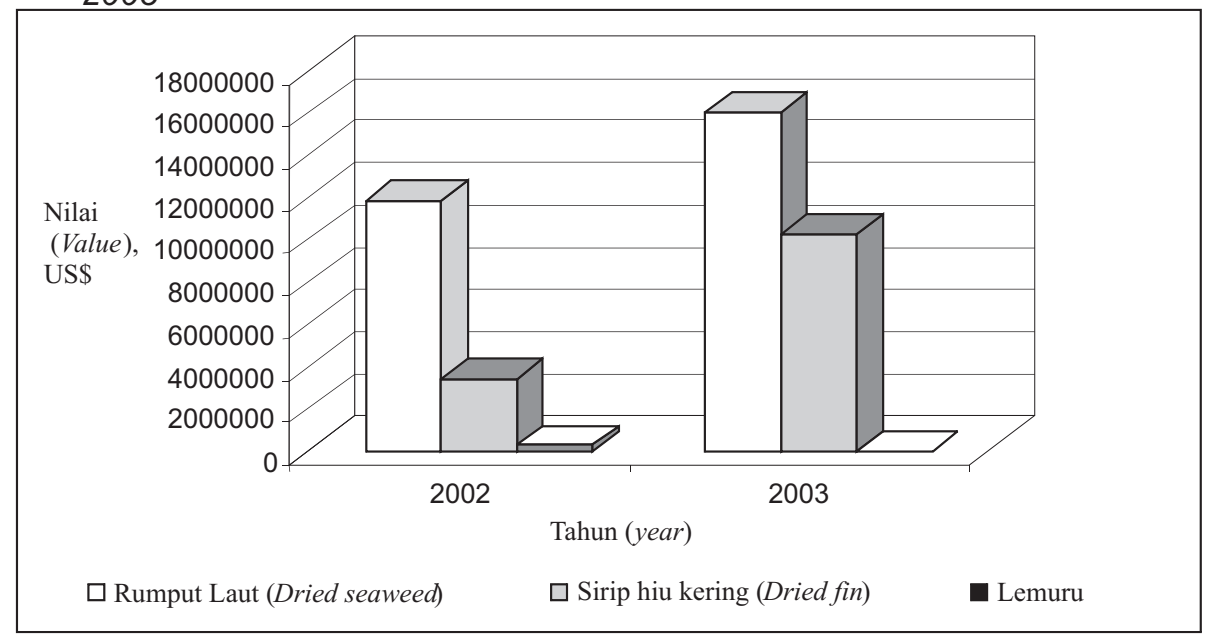

Sumber : Anonim (2003a) \& Anonim (2004b) diolah

Source : Anonimous (2003a) and Anonimous (2004b), processed

Gambar 2. Nilai Ekspor Sirip Cucut dan Dua Komoditas Pembanding di Indonesia, 20022003

Figure 2. Export Value of Shark Fin and Two Comparing Commodities in Indonesia, 2002-2003

cucut, yaitu ikan lemuru. Pada kedua gambar tersebut, terlihat bahwa meskipun volume ekspor produk cucut jauh di bawah volume ekspor rumput laut, nilai yang dihasilkannya tidak jauh berbeda. Sementara itu, terhadap komoditas pembanding lain yang volume ekspornya sama rendah, yaitu lemuru, perbandingan nilai tersebut jauh lebih tinggi daripada perbandingan volumenya. Gambaran tersebut menegaskan bahwa peranan produk cucut dalam ekspor perikanan Indonesia tidak dapat diabaikan. Sebagai catatan, gambaran serupa juga terjadi pada beberapa spesies lain yang masuk dalam 
kategori shark menurut definisi FAO, termasuk di dalamnya ikan pari.

Gambaran tentang besarnya nilai ekspor produk cucut tersebut memberikan penjelasan tentang faktor pendorong penyebab terjadinya kenaikan produksi yang terjadi secara terus menerus pada beberapa periode yang lalu. Dalam kurun waktu antara Tahun 1990 dan Tahun 1997, produksi cucut meningkat rata-rata 2,6\% sedangkan produksi ikan pari mengalami kenaikan lebih tinggi, yaitu sebesar rata-rata $6,7 \%$.

Namun demikian mengacu pada Gambar 3, kenaikan produksi pada periode 1998 s/d 2003 untuk cucut adalah 2,1\% dan untuk ikan pari sebesar 5,8\%. Ini berarti bahwa pada periode terakhir produksi cucut meningkat dalam laju yang melambat, sehingga diperkirakan bahwa pada masa yang akan datang kenaikan tersebut tidak dapat dipertahankan lagi.

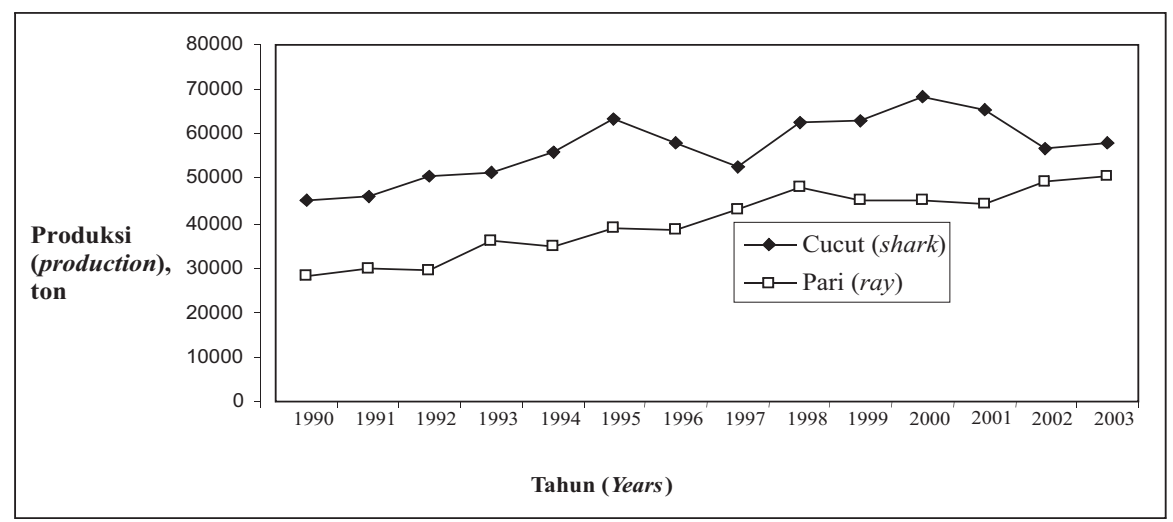

Sumber : Anonim, 2003b diolah

Source : Anonimous (2003b), processed

\section{Gambar 3. Perkembangan Produksi Cucut dan Pari di Indonesia, Periode 90-97 dan} 98-03

Figure 3. Development of Shark and Ray Production in Indonesia, Periods of 90-97 and 98-03

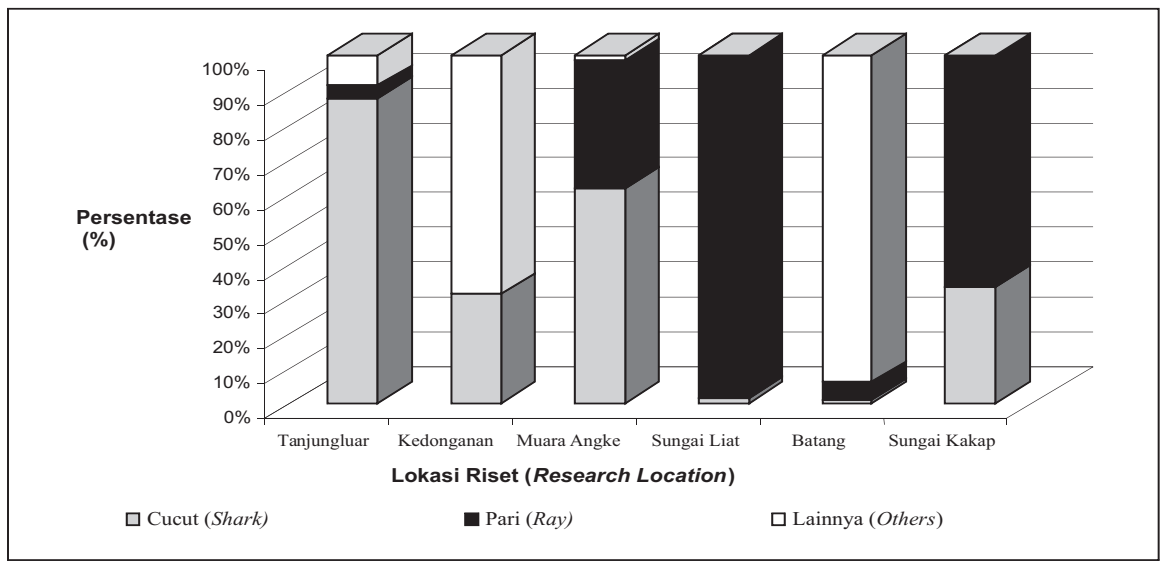

Sumber : data primer, diolah

Source : primary data, processed

\section{Gambar 4. Prosentase Tangkapan Ikan Cucut, Pari dan Lainnya di Lokasi Penelitian,} 2005

Figure 4. Percentage of Shark, Ray and Other Fish Catches at Research Locations, 2005 


\section{Produksi Cucut di Berbagai Lokasi}

Cucut diproduksi di berbagai lokasi melalui kegiatan penangkapan yang menerapkan prioritas target yang berbedabeda. Di lokasi-lokasi tertentu, cucut dan atau ikan pari merupakan target utama sedangkan di wilayah lain merupakan hasil sampingan. Sebagai ilustrasi, Gambar 4 menunjukkan perbedaan prosentase tangkapan rata-rata cucut dan ikan pari yang diperlihatkan oleh data penangkapan di masing-masing lokasi penelitian, nilai ini diperoleh berdasarkan hasil wawancara dengan nahkoda kapal pada saat survey dilakukan.

\section{Nilai Ekonomi Perikanan Cucut dan Ikan Pari}

\section{Nilai ekonomi bagi perikanan setempat}

Terlepas dari target tangkapan utamanya, semua perikanan cucut dan ikan pari memberikan kontribusi yang signifikan terhadap perikanan di wilayah yang bersangkutan. Di wilayah dimana cucut atau pari menjadi target utama, signifikansi dari kontribusi ekonomi tersebut dapat dicontohkan oleh data periknan cucut dan pari di Pangkalpinang. Pangkalpinang merupakan lokasi pendaratan penting di Propinsi Bangka Belitung selain Sungai Liat. Di Pangkalpinang, besarnya hasil penjualan cucut dan pari mencapai nilai yang setara dengan raman yang diperoleh sebuah TPI besar di kota tersebut. Tabel 1 memperlihatkan bahwa perikanan cucut dan ikan pari yang didaratkan di kota tersebut dari tahun ke tahun berkisar antara Rp. 4 sampai Rp. 5 milyar, jumlah yang sangat dekat dengan angka raman yang tercatat pada TPI Pasir Putih, TPI terbesar di Pangkal Pinang.

Kontribusi yang signifikan juga tergambar di wilayah dimana cucut atau pari tidak merupakan target penangkapan utama. Sebagai ilustrasi, Tabel 2 menunjukkan angkaangka perbandingan antara nilai cucut / pari dan raman yang diperoleh TPI terbesar di Batang. Nilai cucut dan pari terhitung tidak kurang dari $10 \%$ dari total raman di TPI terbesar di kota tersebut.

\section{- Nilai ekonomi bagi nelayan}

Nilai ekonomi perikanan cucut bagi nelayan pada kegiatan penangkapan cucut / pari bervariasi tergantung lokasi dan posisi

Tabel 1. Perbandingan Nilai Ikan Cucut dan Pari yang didaratkan di Kota Pangkalpinang dengan Raman di TPI Terbesar Kota Tersebut, 2001-2004

Table 1. Values of Shark and Ray at Pangkalpinang Landing Places as Compared to Revenues Generated by the Biggest Auction Place in the City, 2001-2004

\begin{tabular}{cccccc}
\hline $\begin{array}{c}\text { Tahun I } \\
\text { Year }\end{array}$ & \multicolumn{2}{c}{ Cucut*/Shark } & \multicolumn{2}{c}{ Pari*/Ray } & $\begin{array}{c}\text { Total Raman TPI } \\
\text { Putih Pasir*I }\end{array}$ \\
\cline { 2 - 5 } & $\begin{array}{c}\text { Nilai/value } \\
\text { (Rp. 1000) }\end{array}$ & $\begin{array}{c}\text { Pensentase/ } \\
\text { percentage } \\
(\%)\end{array}$ & $\begin{array}{c}\text { Nilai/value(Rp. } \\
\text { 1000) }\end{array}$ & $\begin{array}{c}\text { Pensentase/ } \\
\text { percentage } \\
\text { (\%) }\end{array}$ & $\begin{array}{c}\text { Revenue of Pasir } \\
\text { Putih Auction Place }\end{array}$ \\
\hline 2001 & 3.101 .000 & 82 & 1.890 .900 & 50 & 3.761 .990 \\
2002 & 3.301 .048 & 53 & 1.976 .981 & 32 & 6.213 .580 \\
2003 & 3.389 .111 & 58 & 1.999 .983 & 34 & 5.811 .980 \\
2004 & 1.030 .126 & 20 & 2.814 .896 & 54 & 5.232 .700 \\
\hline
\end{tabular}

Sumber :*Anonim, 2004; **Anonim, 2004a

Source :*Anonym, 2004; **Anonyim, 2004a 
Tabel 2. Perbandingan Nilai Ikan Cucut dan Pari yang didaratkan di Kota Batang dengan Raman di TPI Terbesar Kota Tersebut, 2001-2003

Table 2. Values of Shark and Ray at Batang Landing Places as Compared to Revenues Generated by the Biggest Auction Place in the City, 2001-2003

\begin{tabular}{|c|c|c|c|c|c|}
\hline \multirow{2}{*}{$\begin{array}{l}\text { Tahun/ } \\
\text { Year }\end{array}$} & \multicolumn{2}{|c|}{$\begin{array}{l}\text { Cucut }{ }^{\star} \text { Shark } \\
\text { Shat }\end{array}$} & \multicolumn{2}{|c|}{$\begin{array}{l}\text { Pari*I } \\
\text { Ray }\end{array}$} & \multirow{2}{*}{$\begin{array}{l}\text { Total Raman TPI } \\
\text { KlidangLor**I } \\
\text { Revenue of } \\
\text { Klidang Lor } \\
\text { Auction Place }\end{array}$} \\
\hline & $\begin{array}{l}\text { Nilai/Value } \\
\text { (Rp. 1000) }\end{array}$ & $\begin{array}{l}\text { Pensentase/ } \\
\text { Percentage (\%) }\end{array}$ & $\begin{array}{l}\text { Nilai/Value } \\
\text { (Rp. 1000) }\end{array}$ & $\begin{array}{c}\text { Pensentase/ } \\
\text { Percentage } \\
(\%)\end{array}$ & \\
\hline 2001 & 854.510 & 2 & 4.408 .220 & 9 & 51.722 .638 \\
\hline 2002 & 449.750 & 1 & 4.444 .730 & 12 & 36.860 .807 \\
\hline 2003 & 82.580 & 0,4 & 3.922 .000 & 18 & 21.320 .562 \\
\hline
\end{tabular}

nelayan tersebut di dalam kepemilikan dan pengoperasian kapal penangkap. Secara rinci, besarnya pendapatan (atau tambahan pendapatan) yang diperoleh pernilik, kapten dan anak buah kapal (ABK), dapat diperkirakan dari besarnya biaya operasional dan penerimaan, sebagaimana ditunjukkan oleh Gambar 5, dan sistem bagi hasil yang berlaku di masing-masing lokasi (Tabel 3).
Tabel 4 menunjukkan besarnya pendapatan (atau tambahan pendapatan) yang diperoleh nelayan, berdasarkan angka biaya operasional dan penerimaan dan sistem bagi hasil sebagaimana ditunjukkan pada Gambar 5 dan Tabel 3. Dari table tersebut terlihat bahwa di lokasi dimana cucut atau pari merupakan target utama, yaitu Tanjung Luar, Sungai Liat, dan Sungal Kakap, setiap ABK

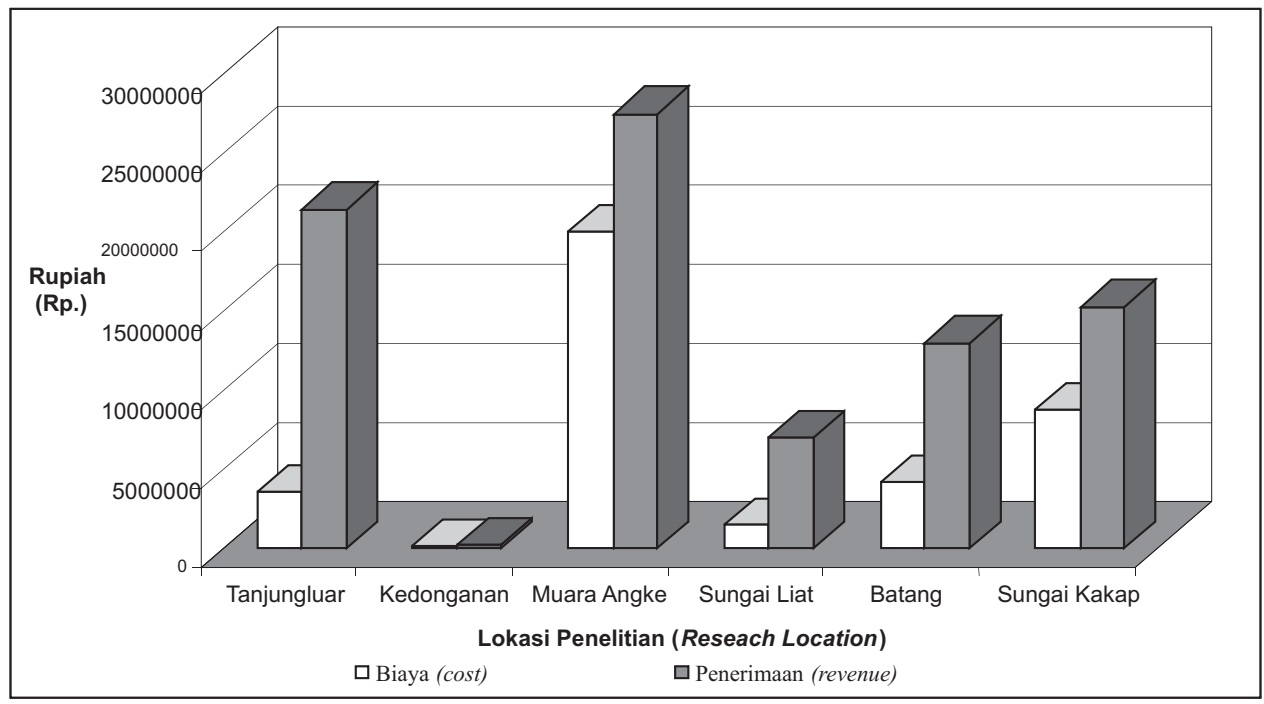

Sumber : Data primer, diolah

Source : primary data, processed

Gambar 5. Biaya Operasional dan Penerimaan Usaha Penngkapan Cucut dan Pari di Lokasi Penelitian, 2005

Figure 5. Operational Cost and Revenue Of Shark And Ray Fishery at Research Locations, 2005 
Tabel 3. Sistem Bagi Hasil di Lokasi Penelitian, 2005

Table 3. Sharing Systems At Research Locations, 2005

\begin{tabular}{|c|c|c|c|c|}
\hline \multirow{2}{*}{$\begin{array}{l}\text { Lokasi } \\
\text { (Location) }\end{array}$} & \multicolumn{4}{|c|}{ Sistem Bagi Hasil (Sharing System) } \\
\hline & $\begin{array}{l}\text { Pemilik/ } \\
\text { Owner }\end{array}$ & $\begin{array}{l}\text { Kapten/ } \\
\text { Skipper }\end{array}$ & $\begin{array}{l}\text { ABKI } \\
\text { Crew }\end{array}$ & $\begin{array}{l}\text { Keterangan/ } \\
\text { Remark }\end{array}$ \\
\hline Tanjung Luar & $\begin{array}{l}2 / 3 \text { bagian dari } \\
\text { keuntungan / } \\
2 / 3 \text { share from } \\
\text { benefit }\end{array}$ & $\begin{array}{l}\text { 1/3 bagian dari keuntungan } \\
\text { dibagi rata untuk sejumlah } \\
\text { ABK + tambahan dari } \\
\text { pemilik / } \\
1 / 3 \text { share from benefit } \\
\text { divide equal for amount } \\
\text { of crews + supplement }\end{array}$ & $\begin{array}{l}1 / 3 \text { bagian dari } \\
\text { keuntungan dibagi rata } \\
\text { untuk sejumlah } A B K / \\
1 / 3 \text { share from } \\
\text { benefit divide equal } \\
\text { for amount of crews }\end{array}$ & $\begin{array}{l}\text { Suplemen kapten ( } \approx 1 \\
\text { bagian ABK) disisihkan da } \\
\text { bagian pemilik / } \\
\text { Skipper's supplement ( } \approx 1 \\
\text { crew's share) is deducted } \\
\text { from owner's share }\end{array}$ \\
\hline Kedonganan & $\begin{array}{l}1 / 2 \text { bagian dari } \\
\text { keuntungan / } \\
1 / 2 \text { share from } \\
\text { benefit }\end{array}$ & & $\begin{array}{l}1 / 2 \text { bagian dari } \\
\text { keuntungan / } \\
1 / 2 \text { share from benefit }\end{array}$ & $\begin{array}{l}\text { Perahu dioperasikan hanya } \\
\text { oleh pemilik dan ABK / Boat } \\
\text { is operated by the owner } \\
\text { and a a crew only }\end{array}$ \\
\hline Muara Angke & $\begin{array}{l}9 / 10 \text { bagian dari } \\
\text { keuntungan / } \\
9 / 10 \text { share from } \\
\text { benefit }\end{array}$ & $\begin{array}{l}1 / 10 \text { bagian dari keuntungan / } \\
1 / 10 \text { share from benefit }\end{array}$ & Rp 18000/day & $\begin{array}{l}\text { Upah ABK diperhitungkan } \\
\text { sebagai biaya operasional / } \\
\text { Crew's wage is considere } \\
\text { an operational cost }\end{array}$ \\
\hline Sungai Liat & $\begin{array}{l}1 / 2 \text { bagian dari } \\
\text { keuntungan / } \\
1 / 2 \text { share from } \\
\text { benefit }\end{array}$ & $\begin{array}{l}1 / 2 \text { bagian dari keuntungan } \\
\text { dibagi rata untuk sejumlah } \\
\text { ABK }+ \text { tambahan dari } \\
\text { pemilik / } \\
1 / 3 \text { share from benefit } \\
\text { divide equal for amount } \\
\text { of crews + supplement }\end{array}$ & $\begin{array}{l}1 / 2 \text { bagian dari } \\
\text { keuntungan dibagi rata } \\
\text { untuk sejumlah } A B K / \\
1 / 2 \text { share from } \\
\text { benefit divide equal } \\
\text { for amount of crews }\end{array}$ & $\begin{array}{l}\text { Suplemen kapten }(\approx 0.5 \\
\text { bagian ABK) disisihkan da } \\
\text { bagian pemilik / } \\
\text { Skipper's supplement }(\approx 0 . \\
\text { crew's share) is deducted } \\
\text { from owner's share }\end{array}$ \\
\hline Batang & $\begin{array}{l}1 / 2 \text { bagian dari } \\
\text { keuntungan / } \\
1 / 2 \text { share from } \\
\text { benefit }\end{array}$ & $\begin{array}{l}1 / 2 \text { bagian dari keuntungan } \\
\text { dibagi rata untuk sejumlah } \\
\text { ABK }+ \text { tambahan dari } \\
\text { pemilik / } \\
1 / 2 \text { share from benefit } \\
\text { divide equal for amount } \\
\text { of crews + supplement }\end{array}$ & $\begin{array}{l}1 / 2 \text { bagian dari } \\
\text { keuntungan dibagi rata } \\
\text { untuk sejumlah } A B K \\
1 / 2 \text { share from / } \\
\text { benefit divide equal } \\
\text { for amount of crews } \\
\text { +supplement }\end{array}$ & $\begin{array}{l}\text { Suplemen kapten }(\approx 0.5 \\
\text { bagian } A B K) \text { disisihkan dari } \\
\text { bagian pemilik / } \\
\text { Skipper's supplement }(\approx 0 \text {. } \\
\text { crew's share) is deducted } \\
\text { from owner's share }\end{array}$ \\
\hline Sungai Kakap & $\begin{array}{l}2 / 3 \text { bagian dari } \\
\text { keuntungan / } \\
2 / 3 \text { share from } \\
\text { benefit }\end{array}$ & $\begin{array}{l}1 / 3 \text { bagian dari keuntungan } \\
\text { dibagi rata untuk sejumlah } \\
\mathrm{ABK}+\text { tambahan dari } \\
\text { pemilik / } \\
1 / 3 \text { share from benefit } \\
\text { divide equal for amount } \\
\text { of crews + supplement }\end{array}$ & $\begin{array}{l}1 / 3 \text { bagian dari } \\
\text { keuntungan dibagi rata } \\
\text { untuk sejumlah } A B K / \\
1 / 3 \text { share from } \\
\text { benefit divide equal } \\
\text { for amount of crews }\end{array}$ & $\begin{array}{l}\text { Suplemen kapten }(\approx 0.5 \\
\text { bagian ABK) disisihkan dari } \\
\text { bagian pemilik / } \\
\text { Skipper's supplement }(\approx 0 . \\
\text { crew's share) is deducted } \\
\text { from owner's share }\end{array}$ \\
\hline
\end{tabular}

Sumber : data primer (diolah), 2005

Source : primary data (processed), 2005 
Tabel 4. Pendapatan Nelayan dari Perikanan Cucut dan Pari di Lokasi Penelitian, 2005 Tabel 4. Fishers Income Generation from Shark and Ray Fishery at Research Location, 2005

\begin{tabular}{|c|c|c|c|c|}
\hline \multirow{2}{*}{$\begin{array}{l}\text { Lokasi / } \\
\text { Location }\end{array}$} & \multicolumn{3}{|c|}{$\begin{array}{c}\text { Pendapatan dari Cucut / Pari / } \\
\text { Income Generated from Shark / Ray Fishery } \\
\text { Rp/tahun (Rp/year) }\end{array}$} & \multirow{2}{*}{$\begin{array}{l}\text { Keterangan / } \\
\text { Remark }\end{array}$} \\
\hline & $\begin{array}{l}\text { Pemilik / } \\
\text { Owner }\end{array}$ & $\begin{array}{l}\text { Kapten I } \\
\text { Skipper }\end{array}$ & $\begin{array}{l}\text { ABK I } \\
\text { Crew }\end{array}$ & \\
\hline Tanjung Luar & 146.076 .000 & 41.734 .000 & 20.860 .000 & 14 trip/thn/year \\
\hline Kedonganan & 27.720 .000 & - & 27.720 .000 & 240 trip/thn/year \\
\hline Muara Angke & 25.352 .000 & 4.472 .000 & 4.320 .000 & 4 trip/thn/year \\
\hline Sungai Liat & 132.864 .000 & 36.240 .000 & 24.144 .000 & 48 trip/thn/year \\
\hline Batang & 142.560 .000 & 35.784 .000 & 22.356 .000 & 36 trip/thn/year \\
\hline Sungai Kakap & 37.500 .000 & 12.800 .000 & 8.500 .000 & 10 trip/thn/year \\
\hline
\end{tabular}

Sumber: data primer (diolah), 2005

Source : primary data (processed), 2005

memperoleh pendapatan berturut-turut sebesar Rp 20,8 juta, Rp 24,1 juta dan Rp 8,5 juta pertahun. Nilai ini hampir sama dengan tambahan pendapatan yang diperoleh ABK di lokasi dimana cucut atau pari merupakan hasil samping (Kedonganan dan Batang), yakni sebesar masing-masing Rp 27,7 juta dan Rp 22,4 juta pertahun. Kekecualian hanya terjadi di Muara Angke; meskipun cucut dan ikan pari merupakan target utama, ABK hanya mendapatkan penghasilan sebesar Rp 4,3 juta perorang pertahun karena penangkapan berlangsung hanya dua bulan pertahun. Pendapatan nakhoda untuk masing-masing lokasi tersebut berkisar antara sama dengan hingga dua kali lipat pendapatan ABK, tergantung sistem bagi hasil yang berlaku.

\section{- Nilai ekonomi bagi kegiatan-kegiatan ekonomi terkait}

Data yang dikumpulkan melalui penelitian ini menunjukkan bahwa bahwa perikanan cucut dan pari juga telah menciptakan ekonomi yang terkait dengan usaha penangkapan spesies tersebut. Meskipun kegiatan-kegiatan ekonomi tersebut tidak ditemukan di semua tempat, data sebagaimana terangkum pada Tabel 5 menunjukkan bahwa di lokasi-lokasi dimana pemanfaatan cucut masih terbatas dapat mengembangkan kegiatan-kegiatan usaha seperti yang terjadi di lokasi lain. Perkiraan penerimaan pertahun dihitung berdasarkan rata-rata pendapatan bersih yang diperoleh pada setiap kali waktu produksi dikalikan dengan frekuensi produksi per tahun. Ini berarti, perikanan cucut dan pari berpeluang untuk memberikan kontribusi ekonomis yang lebih besar.

Kemungkinan optimalisasi pemanfaatan hasil tangkapan cucut dan pari paling tidak dapat merujuk pada adanya peluang untuk peningkatan pemanfaatan berbagai bagian tubuh cucut dan pari sebagaimana telah dilakukan pelaku usaha di berbagai lokasi. Sebagai contoh, mengacu pada Gambar 6, pemanfaatan daging cucut di Tanjung Luar, Batang dan Sungai Kakap dapat ditingkatkan dari kondisi sekarang (20\%) ke kondisi yng telah dicapai oleh Kedonganan, Muara Angke dan Sungai Liat (50\%). Sementara itu, mengacu pada Gambar 7, pemanfaatan kulit pari sebagaimana telah dilakukan di Batang dan Sungai Kakap dapat 
Tabel 5. Kegiatan Ekonomi Terkait yang Berkembang di Lokasi Penelitian, 2005

Table 5. Related Economic Activities in Research Locations, 2005

\begin{tabular}{|c|c|c|}
\hline $\begin{array}{l}\text { Jenis Kegiatan / } \\
\text { Type of Activity }\end{array}$ & Lokasi / Location & $\begin{array}{l}\text { Perkiraan penerimaan } \\
\text { (Rp/orang/tahun)/ } \\
\text { Predicted revenue } \\
\text { (Rp./person/year) }\end{array}$ \\
\hline $\begin{array}{l}\text { Pemanggang Daging Pari dan } \\
\text { Cucut / Grilled Shark and Ray } \\
\text { Processor) }\end{array}$ & Batang, Jawa Tengah & $\begin{array}{l}\text { Rp } 2 \text { juta /tahun } \\
\text { / million/year }\end{array}$ \\
\hline $\begin{array}{l}\text { Pengasin Daging Pari dan } \\
\text { Cucut / Salted Shark and Ray } \\
\text { Processor) }\end{array}$ & $\begin{array}{l}\text { Pangkalpinang, Bangka } \\
\text { Belitung }\end{array}$ & $\begin{array}{l}\text { Rp } 32 \text { juta /tahun } \\
\text { / million/year }\end{array}$ \\
\hline $\begin{array}{l}\text { Pengolah Kulit Pari / Ray Skin } \\
\text { Processor }\end{array}$ & $\begin{array}{l}\text { Pangkalpinang, Bangka } \\
\text { Belitung }\end{array}$ & $\begin{array}{l}\text { Rp } 12 \text { juta/tahun } \\
\text { / million/year }\end{array}$ \\
\hline $\begin{array}{l}\text { Pem-Fillet Daging Pari dan } \\
\text { Cucut (Shark and Ray Fillet } \\
\text { Processor) }\end{array}$ & $\begin{array}{l}\text { Pangkalpinang, Bangka } \\
\text { Belitung }\end{array}$ & $\mathrm{Rp} 17.000 / \mathrm{kg}$ \\
\hline $\begin{array}{l}\text { Pedagang Eceran } \\
\text { (Small Retailer) }\end{array}$ & $\begin{array}{l}\text { Muara Kintap, } \\
\text { Kalimantan Selatan }\end{array}$ & Rp 65000/hari/day \\
\hline $\begin{array}{l}\text { Pedagang Partai Besar / } \\
\text { Wholesaler }\end{array}$ & $\begin{array}{l}\text { Kurau, Kalimantan } \\
\text { Selatan }\end{array}$ & Rp 2.265.000/bulan/month \\
\hline $\begin{array}{l}\text { Kuli Angkut / } \\
\text { Transporting Labor }\end{array}$ & Tanjung Luar, NTB & $\begin{array}{l}\text { Rp 1000/orang/cucut } \\
\text { / person/shark }\end{array}$ \\
\hline Kuli Bongkar / Unloading Labor & Muara Angke, Jakarta & Rp 300/cucut/shark \\
\hline Jasa Gerobak / Rickshaw Service & Muara Angke, Jakarta & $\begin{array}{l}\text { Rp 8.000/gerobak } \\
\text { /rickshaw }\end{array}$ \\
\hline Kuli muat / Loading Labor & $\begin{array}{l}\text { Muara Angke, Jakarta } \\
\text { Tanjung Luar, NTB }\end{array}$ & Rp 2.000/truk/truck \\
\hline
\end{tabular}

Sumber : Data Primer (Diolah), 2005

Source : Primary Data (Processed), 2005

diintroduksikan dan dikembangkan di Tanjung Luar, Kedonganan, Muara Angke, dan Sungai Liat.

\section{Implikasi pada Pengelolaan Sumberdaya}

Dokumen IPOA menekankan keharusan negara-negara pengadopsi dokumen tersebut untuk melakukan upayaupaya optimalisasi manfaat cucut yang tertangkap. Limbah harus ditekan semaksimal mungkin sedangkan nilai tambah dari produk harus diupayakan setinggi mungkin. Paparan di atas menunjukkan bahwa sejauh ini hasil tangkapan cucut dan pari di berbagai lokasi pendaratan di Indonesia hanya termanfaatkan sebagian dan nilai tambahnya pun masih sangat terbatas. Di banyak lokasi, penangkapan cucut bahkan dilakukan hanya untuk mendaratkan bagian yang paling bernilai ekonomis, misalnya sirip; sementara itu, bagian lain seperti daging, kulit maupun tulang seringkali dibuang di laut. Hal ini 


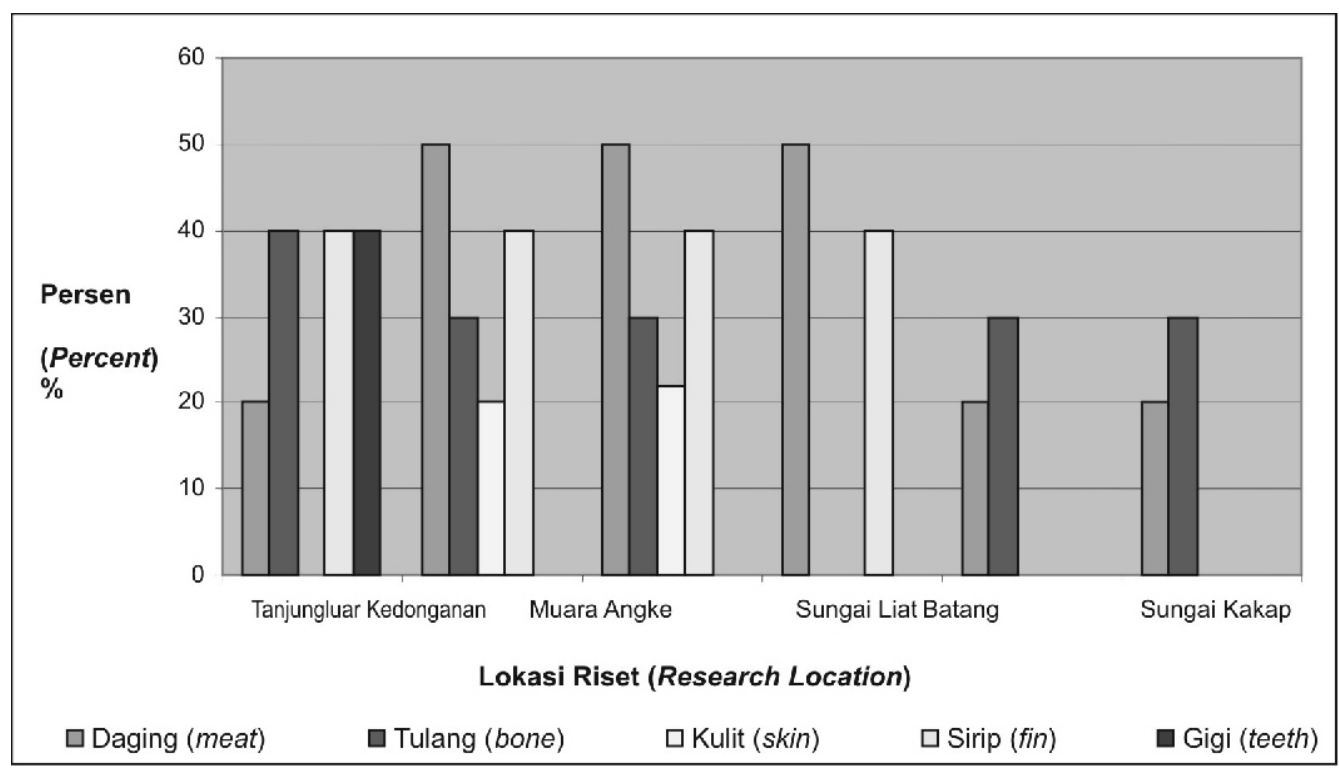

Gambar 6. Persentase Pemanfaatan Berbagai Bagian Cucut di Lokasi Penelitian, 2005 Figure 6. Percentage of Utilization of Shark's Parts at Research Locations, 2005

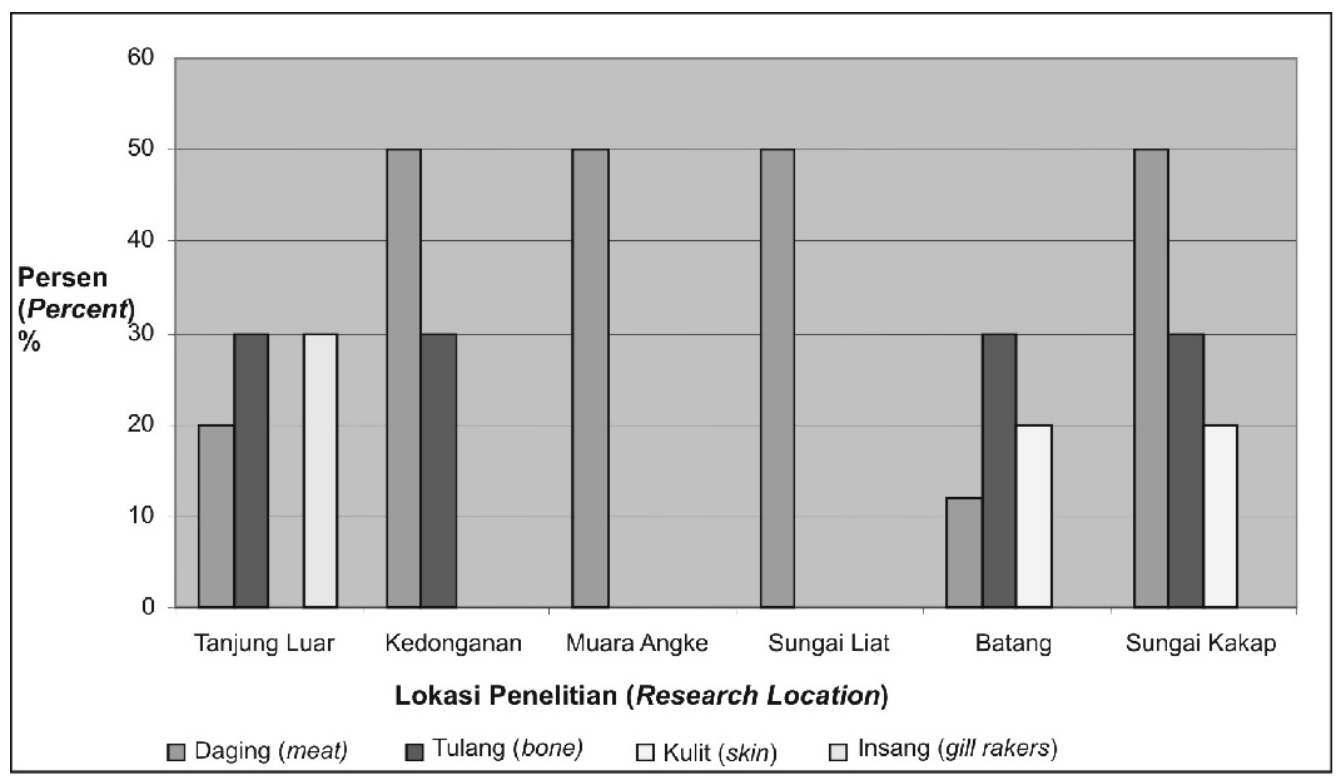

Gambar 7. Persentase Pemanfaatan Bagian-Bagian Ikan Pari di Lokasi Penelitian, 2005

Figure 7. Percentage of Utilization of Ray's Parts at Research Location, 2005 
dilakukan karena nilai ekonomis bagian yang dibuang dipandang rendah oleh nelayan bahkan tidak bernilai sama sekali. Pengetahuan dan keterampilan yang minim dalam hal pengolahan produk bernilai tambah mengakibatkan nilai ekonomi yang seharusnya dapat dinikmati oleh nelayan terbuang percuma, disisi lain sumberdaya ikan cucut dan pari semakin menurun akibat pengelolaan yang belum optimal.

Dalam hubungannya dengan pengadopsian prinsip-prinsip IPOA untuk konteks Indonesia, gambaran angka-angka di atas menunjukkan bahwa pencantuman rumusan yang tidak tepat akan berakibat sangat negatif pada penerimaan perikanan di berbagai lokasi. Sebagaimana dimaksudkan dalam dokumen IPOA, fokus perhatian dari IPOA yang akan diimplementasikan melalui NPOA di berbagai negara adalah keberlanjutan sumberdaya cucut. Dengan demikian, berbagai hal atau tindakan yang dianggap perlu disarankan untuk dilakukan demi untuk mengamankan kepentingan keberlanjutan sumberdaya tersebut. Ini berarti bahwa bilamana dipandang perlu, pengelolaan yang bersifat sangat konservatif dan menomorduakan kepentingan pengguna pun dapat dipertimbangkan, sepanjang sumberdaya dapat diselamatkan sesuai dengan salah satu tujuan yang ingin dicapai seperti yang tertera dalam NPOA yaitu Menjamin bahwa tangkapan cucut dari perikanan diatur dan tidak diatur dilakukan secara berkelanjutan.

Jelas bahwa fakta di atas menujukkan relevansi dari pendekatan yang lebih baik, yaitu pendekatan yang tidak hanya mengedepankan sumberdayanya, melainkan juga harus memperhatikan kepetingan manusianya. Terkait dengan hal ini, telah pula diingatkan oleh Charles (1994) bahwa tolok ukur keberhasilan pembangunan perikanan mencakup 4 aspek utama, yang diistilahkan sebagai segitiga keberlanjutan, yaitu aspek ekologis, aspek sosial-ekonomi, aspek komunitas, dan aspek institusional.

Mengingat kepentingan yang besar dari eksistensi perikanan cucut pada kehidupan ekonomi nelayan, mengubah atau memaksakan perilaku tertentu tidak mudah. Dengan demikian, diperlukan strategi yang tepat untuk melaksanakannya. Menimbang bahwa seperti ditunjukkan pada hasil penelitian ini, kepentingan utama nelayan dalam pemanfataan ikan cucut adalah dari nilai ekonomi, maka strategi yang dipilih pun perlu disesuaikan dengannya. Misalnya, sebuah strategi dapat dikaitkan dengan optimalisasi pemanfaatan hasil tangkapan melalui pengembangan berbagai kegiatan pengolahan dan perbaikan-perbaikannya. Strategi lain adalah dengan membuka peluang usaha lain, yang memberikan alternatif sepadan terhadap kegiatan penangkapan cucut dan kegiatan-kegiatan usaha derivatnya.

Strategi-strategi tersebut tidak boleh terlepas dari arahan-arahan yang tercantum dalam IPOA, yang ditujukan untuk pelestarian sumberdaya. Dalam klausul IPOA, perkembangan apapun yang terjadi dari tahun ke tahun harus tercatat dan terlaporkan karena perkembangan negatif dalam waktu singkat pun dapat merupakan indikator yang baik untuk memprediksikan terjadinya awal penurunan produksi yang membahayakan kelestarian. Ini berarti bahwa strategi-strategi tersebut harus sedapat mungkin menghindari langkah-langkah yang menyebabkan terjadinya penurunan produksi.

\section{KESIMPULAN}

Berdasarkan hasil analisis terhadap pemanfaatan cucut dan ikan pari yang dilakukan oleh nelayan penangkap di lokasi penelitian diperoleh informasi bahwa produksi cucut dan ikan pari memberikan kontribusi signifikan terhadap pendapatan nelayan, baik 
yang menangkap cucut sebagai target utama maupun hasil sampingan. Di lokasi dimana cucut atau pari merupakan target utama, yaitu Tanjung Luar, Sungai Liat, dan Sungai Kakap, setiap ABK memperoleh pendapatan yang nilainya sebanding dengan tambahan pendapatan yang diperoleh $A B K$ di lokasi dimana cucut atau pari merupakan hasil samping (Kedonganan dan Batang). Perkecualian hanya terjadi di Muara Angke, yang meskipun cucut dan pari merupakan target utama, pendapatan ABK tidak sebesar yang diperoleh di Tanjung Luar, Sungai Liat dan Sungai Kakap, suatu hasil yang terkait dengan rendahnya frekuensi penangkapan yang dilakukan. Nilai ekonomi perikanan cucut dan pari juga terkait dengan nilai tambah dari aktivitas pengolah, pengrajin, tukang potong, kuli angkut, dsb. Hasil analisis selanjutnya menunjukkan adanya peluang untuk menyusun sebuah NPOA yang selaras dengan kepentingan ekonomi nelayan, misalnya dengan meningkatkan nilai tambah hasil tangkapan sehingga penurunan volume tangkapan tidak harus menyebabkan turunnya pendapatan. Sejauh ini, sebagian perikanan memiliki nilai tambah yang sangat rendah; misalnya, 3,5 \% untuk cucut dan 23\% untuk pari di Kedonganan, jauh dibawah nilai tambah cucut di Sungai Kakap (290\%) dan pari di Batang (75\%). Implikasi dari hasil ini adalah pentingnya upaya penciptaan nilai tambah disamping perlunya kajian lanjutan untuk merumuskan mekanisme teknis untuk mengurangi volume produksi sesuai dengan kondisi lapang.

\section{DAFTAR PUSTAKA}

Anonim, 2006. Draft National Plan of Action for Shark Management. Direktorat Sumberdaya Ikan, Ditjen Perikanan Tangkap, Departemen Kelautan dan Perikanan.
Anonim, 2005. Laporan Lelang Tempat Pelelangan Klidang Lor, Batang

Anonim, 2004. Statistik Perikanan Pangkalpinang, Dinas Kelautan dan Perikanan Kota Pangkalpinang.

Anonim, 2004a. Laporan Lelang Tempat Pelelangan Ikan Pasir Putih, Pangkal Pinang 2004

Anonim, 2004b. Statistik Ekspor-impor hasil perikanan Tahun 2004. Direktorat Pemasaran Hasil Laut dan Ikan, Ditjen PK2P

Anonim, 2004c. Statistik Perikanan Batang, Dinas Kelautan dan Perikanan Kabupaten Batang

Anonim, 2003a. Statistik Ekspor-Impor hasil perikanan Tahun 2002. Direktorat Pemasaran Hasil Laut dan Ikan, Ditjen PK2P

Anonim, 2003b. Statistik Perikanan Tangkap Indonesia 2001, Direktorat Jenderal Perikanan Tangkap - DKP, 2003

Anonim, 1998. International Plan of Action for the Conservation and Management of Sharks. Food and Agriculture Organization of the United Nation.

Charles, A.T. 1994 Toward sustainability: The fishery experience. Ecological Economics no. 11:201-211.

Kusyanto,J. 2001. Pengembangan Produk Perikanan Sebagai Strategi Memperluas Pemasaran Berorientasi Ekspor Maupun Lokal. Makalah Falsafah Sains (PPs 702) Program Pasca Sarjana / S3. Institut Pertanian Bogor. Bogor.

Purbayanto, A. 2003. Pengembangan Industri Perikanan Tangkap Berwawasan Lingkungan. Makalah Kuliah Proses Produksi Dalam Pemanfaatan Sumberdaya Kelautan Dan Perikanan. Institut Pertanian Bogor. Bogor.

Traffic East Asia, 2004. Shark Product Trade in Hongkong and Mainland China and Implementation of The Cites Shark Listing. 